\title{
Quantitative study of the relationships among proteolysis, lipid oxidation, structure and texture throughout the dry-cured ham process
}

\author{
Rami Harkouss ${ }^{a}$, Thierry Astruc ${ }^{\mathrm{a}}$, André Lebert ${ }^{\mathrm{b}}$, Philippe Gatellier ${ }^{\mathrm{a}}$, Olivier Loison ${ }^{\mathrm{a}}$, Hassan Safa ${ }^{\mathrm{a}}$, \\ Stéphane Portanguen ${ }^{\mathrm{a}}$, Emilie Parafita ${ }^{\mathrm{c}}$, Pierre-Sylvain Mirade ${ }^{\mathrm{a}, *}$ \\ a INRA, UR370 Qualité des Produits Animaux, F-63122 Saint-Genès-Champanelle, France \\ ${ }^{\mathrm{b}}$ Institut Pascal, UMR6602 UBP/CNRS/IFMA, 24 avenue des Landais, BP80026, 63171 Aubière Cedex, France

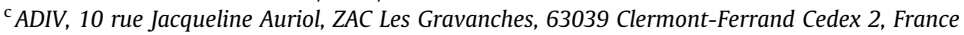

\section{A R T I C L E I N F O}

\section{Article history:}

Received 18 November 2013

Received in revised form 30 April 2014

Accepted 4 June 2014

Available online 21 June 2014

\section{Keywords:}

Dry-cured ham

Proteolysis

Structure

Texture

Polynomial regression model

\begin{abstract}
A B S T R A C T
Temperature, salt and water contents are key processing factors in dry-cured ham production. They affect how proteolysis, lipid oxidation, structure and texture evolve, and thus determine the sensory properties and final quality of dry-cured ham. The aim of this study was to quantify the interrelationships and the time course of (i) proteolysis, (ii) lipid oxidation, (iii) five textural parameters: hardness, fragility, cohesiveness, springiness and adhesiveness and (iv) four structural parameters: fibre numbers, extracellular spaces, cross section area, and connective tissue area, during the dry-cured ham process. Applying multiple polynomial regression enabled us to build phenomenological models relating proteolysis, salt and water contents to certain textural and structural parameters investigated. A linear relationship between lipid oxidation and proteolysis was also established. All of these models and relationships, once combined with salt penetration, water migration and heat transfer models, can be used to dynamically simulate all of these phenomena throughout dry-cured ham manufacturing.
\end{abstract}

(c) 2014 Elsevier Ltd. All rights reserved.

\section{Introduction}

Dry-cured ham can be an important source of essential amino acids for humans. Proteolysis, one of the main biochemical reactions during dry-cured ham processing, is considered to be the source of many of these free amino acids. Proteolysis generally refers to endogenous enzyme activity (Cordero \& Zumalacarregui, 2000), such as that of cathepsins B, L, H and D, calpains, peptidases and cytosolic enzymes (Luccia et al., 2005). Proteolytic activity depends on many factors. Zhao et al. (2005) found that potential activities of cathepsin $\mathrm{B}$ and $\mathrm{L}$ were reduced during processing to only $9.3 \%$ and $13.7 \%$ of their original potential activity, as a result of the inhibitory role of salting. According to Morales, Serra, Guerrero, and Gou (2007), temperature also has a strong influence on these enzymes. They showed that ageing biceps femoris (BF) muscle, at $30^{\circ} \mathrm{C}$, increased proteolysis intensity significantly compared with hams aged at $5{ }^{\circ} \mathrm{C}$. It has also been observed that high temperatures during the drying-ageing stage promote the formation of non-protein nitrogen compounds and, in turn, affect the course of proteolysis. Many authors have found that

\footnotetext{
* Corresponding author. Tel.: +33 473624592; fax: +33 473624089.

E-mail address: pierre-sylvain.mirade@clermont.inra.fr (P.-S. Mirade).
}

proteolysis rate is affected by several processing parameters, such as temperature, relative air humidity and salt content (Arnau, Gou, \& Comaposada, 2003; Ruiz-Ramirez, Arnau, Serra, \& Gou, 2006; Toldrá, Flores, \& Sanz, 1997). High water content has been found to increase proteolytic activity as a result of high water activity $\left(a_{\mathrm{w}}\right)$ values (Serra, Ruiz-Ramírez, Arnau, \& Gou, 2005). In addition, some studies have shown that proteolysis remains stable during one week of storage at $30^{\circ} \mathrm{C}$ and increases after one month of storage under the same conditions (Arnau, Guerrero, \& Gou, 1997; Morales et al., 2007). The anatomic location of muscles inside the ham, whether external, e.g. semimembranosus (SM), or internal, e.g. BF, also plays a major role in the time course of proteolysis during the dry-cured ham production process, owing to different salt and water transfer kinetics in each muscle. Very recently, Harkouss, Safa, Gatellier, Lebert, and Mirade (2014) have developed phenomenological models allowing proteolysis (through a proteolysis index) to be quantified, in five different pork muscles, as a function of temperature and water and salt contents. Using these statistical models, these authors predicted that the highest increase in proteolysis occurred during the last stage of the drycured ham process (ageing), with a mean monthly PI augmentation of $2-2.5 \%$. It is well-known that proteolysis impacts the final texture (hardness, cohesiveness) of the product, and is considered 
as a crucial parameter for obtaining good quality sensory characteristics at the end of the process (Garcra-Garrido, Quiles-Zafra, Tapiador, \& Luque de Castro, 2000; Toldrá, 1998; Zhao et al., 2008). Thus, a better understanding and control of proteolysis rates can favour an optimised texture in dry-cured ham.

In parallel, lipid oxidation, which is an important biochemical phenomenon that occurs in foods during processing and storing, strongly affects (negatively, but also positively) their quality and chemical safety (Jin et al., 2012). Lipid oxidation is also an essential factor and has a positive impact on the development of the typical aroma of dry-cured ham. Many research studies have characterised lipid oxidation in food products or examined the effect of $\mathrm{NaCl}$ and temperature on it (Aidos, Lourenco, Van der Padt, Luten, \& Boom, 2002; Jin et al., 2012; Rhee, Smith, \& Terrell, 1983, among others). Indeed, in minced pork muscles, Rhee et al. (1983) showed that $\mathrm{NaCl}$ inhibited lipid oxidation at concentrations higher than $2 \%$, but promoted it at lower concentrations. Aidos et al. (2002) found that elevating temperature could accelerate the degradation of hydroperoxides in crude herring oil. Recently, Jin et al. (2012) reported that, even at $4 \%$ salt content, lipid oxidation gradually increased in minced pork muscles, but this varied according to the process temperature; in other words, lipid oxidation is strongly affected by both salt content and temperature, and probably by their interaction. Jin et al. (2012) confirmed that, as the temperature increased, so the threshold value of $\mathrm{NaCl}$ content affecting lipid oxidation in pork muscle progressively decreased.

In general, the sensory quality of dry-cured ham is evaluated through flavour, appearance and texture criteria. Although colour and flavour are highly important for reaching a high final product quality, texture remains a major sensory characteristic to be tested. Texture problems, such as softness, pastiness and crusting, frequently impede slicing and give a mouth-coating sensation, underlining the important role of texture for both retailer and consumer acceptability. Hams are usually classified into four texture types: very pasty, pasty, soft, and normal, each identified by various properties. It has been shown that textural defects are closely related to anomalous proteolysis (Virgili, Parolari, Schivazappa, Soresi-Bordini, \& Borri, 1995). Studies have shown that nonprotein nitrogen (NPN) values are highest in pasty hams and lowest in soft hams. Ruiz-Ramirez, Serra, Gou, and Arnau (2005) observed that high proteolysis rates led to poor cohesiveness and sliceability, as a result of abnormal softness. The role of several process factors (e.g. salt content, temperature) on texture has also been investigated. Gou, Morales, Serra, Guàrdia, and Arnau (2008) studied the effect of salt, and observed that, as $\mathrm{NaCl}$ content decreased, so texture problems increased; these results were in line with those of Desmond (2006), who showed that limiting salt concentration tended to decrease fibre swelling, leading to poor texture. Also, Sforza et al. (2001) showed that high temperature in the final ageing period played an important role in lowering ham dryness. These results were confirmed by Morales, Arnau, Serra, Guerrero, and Gou (2008), who observed a decreased pastiness in BF with no increased hardness in SM muscle, after one week of storage at $30^{\circ} \mathrm{C}$. Most texture problems in dry-cured hams could be related to a short processing time and low salt content. Consequently, studies have to be more narrowly focussed on processing factors (time, temperature, salt amount), in association with textural properties (e.g. hardness) and biochemical changes (proteolysis, oxidations, lipolysis) to ensure a dry-cured ham of high final quality. To achieve this aim, structural properties must also be thoroughly studied and combined with the properties stated above.

Few studies have been carried out to study the main biochemical changes influencing the structural proteins, especially those related to the thick and thin filaments, the Z-disks and the costamere proteins (Fritz, Mitchell, Marsh, \& Greaser, 1993). Electron microscopy highlighted the effect of endogenous proteolytic enzymes on muscle ultrastructure during dry-cured ham processing. Using this technique, in combination with gas chromatography, Larrea, Perez-Munuera, Hernando, Quiles, and Lluch (2007) related dry-cured ham quality to its microstructure, and observed modifications in the structural proteins that could explain the texture and flavour time course of the final product. They reported that, after the salting stage, the Z-disks inside the myofibrils were no longer in line, and a marked degradation of the cell membranes was detected; in the last stage of ripening, several accumulated proteolysis products were observed. This brief literature review shows that little quantitative information about the interrelationships between proteolysis, texture and/or structure is available.

Here we aim to study lipid oxidation and devise phenomenological models, quantitatively, relating proteolysis to several textural and/or structural parameters, through a statistical analysis of experimental results obtained on samples extracted from industrial dry-cured ham at five key times during their manufacture. These phenomenological models will be implemented, at the end, into a numerical finite-element model dedicated to predicting heat and mass transfer phenomena and coupling them with proteolysis index (PI) calculation, using other phenomenological models recently published (Harkouss et al., 2014), with the objective of simulating all that happens in a 3D dry-cured ham during its elaboration process.

\section{Materials and methods}

\subsection{Extraction of samples of Bayonne dry-cured hams}

The work described here evaluates changes in the time course of proteolysis, lipid oxidation, texture and structure that occur in PDO (Protected Designation of Origin) Bayonne dry-cured hams during their manufacture. In total, 15 Bayonne dry-cured hams were selected, on the basis of an initial $\mathrm{pH}$ value in the range 5.6-5.9, corresponding to three hams removed from the process at five different processing times: (i) four days post mortem ("fresh hams"); (ii) at the end of the resting period (11 weeks); (iii) at the end of the drying period (21 weeks); (iv) at mid-period ( 35 weeks);and (v) at the end of the ageing period (12 months). The five processing times were chosen in order to obtain five very different levels of proteolysis. These hams were purchased from Pyragena (Arzacq, Pyrénées-Atlantiques, France), an experimental centre producing and working on Bayonne dry-cured hams. At a distance of $10 \mathrm{~cm}$ from the coaxial bone, a $3 \mathrm{~cm}$-thick cross sectional area section was cut on each of the 15 hams (Fig. 1a). On each section, two slabs $(2 \times 3 \times 5 \mathrm{~cm})$ of muscle were cut: the first $2 \mathrm{~cm}$ from the bottom in the BF muscle, and the second $2.5 \mathrm{~cm}$ from the top of the ham in the SM muscle (Fig. 1b). In this way, we expected to have similar salt and water contents in all the samples obtained from each ham for the various experimental measurements, and to keep constant the geometrical position where the samples were cut for the 15 dry-cured hams. Each muscle slab was then divided into various samples: $2 \times 1 \mathrm{~g}$ for the quantification of proteolysis ( $n=2 \times 3=6$, per muscle per time), $1 \mathrm{~g}$ for the quantification of lipid oxidation ( $n=3$, per muscle per time), $1 \mathrm{~g}$ for the determination of salt content ( $n=3$, per muscle per time), about 2 or $3 \mathrm{~g}$ for the determination of water content $(n=3$, per muscle per time), one sample of $2 \times 3 \times 0.5 \mathrm{~cm}$ dedicated to structural analysis and the rest of the slab was cut into two large samples dedicated to texture analysis $(n=2 \times 3=6$, per muscle per time). All the samples were then vacuum-packed in plastic bags and frozen at $-80^{\circ} \mathrm{C}$ until needed, except the samples dedicated to structural analysis that were treated separately (Section 2.3.1) and those dedicated to water content measurement that were placed directly in a laboratory controlled-temperature chamber, after being weighed. 


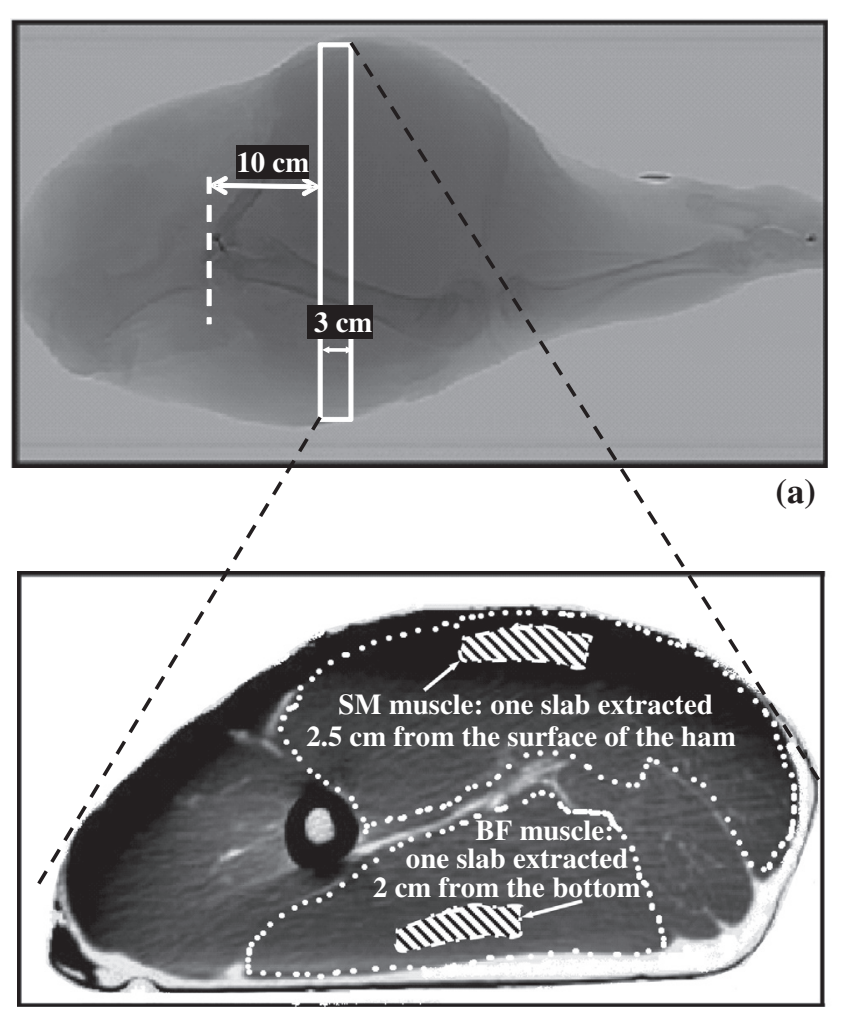

(b)

Fig. 1. View of the location where the samples were extracted from the 15 industrial dry-cured hams: (a) general view corresponding to a fresh ham and showing precisely where each $3 \mathrm{~cm}$-thick cross sectional area was cut; and (b) view of the cross sectional area cut performed on each dry-cured ham, with the location where the SM and BF muscle slabs were extracted.

\subsection{Biochemical measurements}

\subsubsection{Quantification of proteolysis}

The proteolysis index (PI) of dry-cured ham samples was determined to evaluate the proteolysis intensity, using the fluorometricbased procedure described by Harkouss, Mirade, and Gatellier (2012). Briefly, this procedure comprises the following successive phases: (i) grinding of the samples; (ii) dilution of the extracts with trichloroacetic acid to precipitate proteins; (iii) centrifuging; (iv) measurement of the peptide and amino acid concentrations in a portion of the supernatant; (v) addition of fluorescamine to another portion of the supernatant; and (vi) $1 \mathrm{~h}$ later, measurement of fluorescence, and determination of the level of amino groups by reference to a calibration curve of glycine treated in parallel, under exactly the same conditions as the pork meat extracts. This procedure determines the level of $\mathrm{N}$-terminal $\alpha$-amino groups of peptides and amino acids, and so reflects the real intensity of proteolytic activity occurring in the hams throughout the drying and curing processes. PI was defined as the percent ratio of $\mathrm{N}$-terminal $\alpha$-amino group content to total protein content of the ham sample. A more complete description of this powerful and rapid technique for quantifying proteolysis can be found in Harkouss et al. (2012). It is noteworthy that, determination of proteolysis using this fluorometric-based procedure is more sensitive and specific than is the classic nitrogen method and it could be used directly in industry on small amounts of meat $(\leqslant 0.5 \mathrm{~g})$. Moreover, we found a correlation between the two PI values (Harkouss et al., 2012), thus allowing us to exploit the correlations established in this study.

\subsubsection{Quantification of lipid oxidation}

Lipid oxidation was quantified via 2-thiobarbituric acidreactive substances (TBARS). TBARS were determined, using the method developed by Mercier, Gatellier, Viau, Remignon, and Renerre (1998) based on the technique of Lynch and Frey (1993). Muscle samples $(1 \mathrm{~g})$ were homogenised with $10 \mathrm{ml}$ of deionised distilled water, using a Polytron blender ( $1 \mathrm{~min}$ at medium speed). Homogenates $(0.5 \mathrm{ml})$ were incubated with $1 \%(\mathrm{w} / \mathrm{v}) 2$-thiobarbituric acid in $50 \mathrm{mM} \mathrm{NaOH}(0.25 \mathrm{ml})$ and $2.8 \%(\mathrm{w} / \mathrm{v})$ trichloroacetic acid $(0.25 \mathrm{ml})$ in a boiling water bath, for $10 \mathrm{~min}$. After cooling at room temperature for $30 \mathrm{~min}$, the pink chromogen was extracted with n-butanol $(2 \mathrm{ml})$, and its absorbance measured at $535 \mathrm{~nm}$ against a blank of n-butanol. TBARS concentrations were calculated, using 1,1,3,3 tetraethoxypropane $(0-0.8 \mu \mathrm{M})$ as standard. Results are expressed as mg of MDA per $\mathrm{kg}$ of meat (TBA units).

\subsection{Structural analyses}

\subsubsection{Preparation of dry-cured ham samples}

The dry-cured ham samples were frozen in cooled isopentane $\left(-160^{\circ} \mathrm{C}\right)$ chilled with liquid nitrogen $\left(-196^{\circ} \mathrm{C}\right)$, and stored at $-80^{\circ} \mathrm{C}$ prior to analysis. Serial fibre cross-sections $10 \mu \mathrm{m}$ thick were sliced at $-25^{\circ} \mathrm{C}$ in a cryostat (Microm HM 560, Thermo Fisher Scientific Inc., United States), mounted on glass slides, and then airdried at $20^{\circ} \mathrm{C}$. Sections were stained with hematoxylin-eosinsafran (HES) to reveal general structure, and with picro-Sirius red to reveal perimysial and endomysial collagen. After staining, the slices were mounted using a synthetic resin (Eukitt, Kindler $\mathrm{GmbH}$ \& Co, Germany) to preserve the section.

\subsubsection{Acquisition and analysis of images}

Observations were made on a transmission microscope coupled to a digital acquisition kit (Olympus BX61 microscope, Olympus DP 71 digital camera and Cell F software, Olympus France SAS, Rungis, France). Images were recorded at $10 \times$ magnification. The $10 \times$-magnified cross section images were quantitatively analysed with the open source ImageJ image processing software, applying the exact same acquisition parameters for all the images. Each RGB-coloured image was separated into its three monochromatic components (red, green and blue) to keep only the green component of the image, thereby improving the contrast between extracellular space and muscle fibres. To prevent distortion of the fibre size evaluation, the only fields of observation taken into account were those where muscle fibres were perfectly cut transversely to the main axis of fibre orientation.

Fibre morphology parameters and extracellular spaces were determined on six HES stained images corresponding to six different optical fields, forming a total of approximately 500 muscle fibres for each drying condition. Extracellular space was extracted after thresholding segmentation of the gray levels. Its relative area was assessed by its pixel count relative to the whole field-of-view area. The same approach was used to extract and individualise muscle fibres, eliminating any cropped cells touching the edge of each field of view. The surface area of each fibre was assessed by its pixel count. A conversion factor was applied to express the measured surface areas in $\mu^{2}$. Connective tissue area was determined, in the same way, on six picro-Sirius red-stained images, corresponding to six different optical fields.

\subsection{Texture profile analysis (TPA) test}

Before texture measurement, all the dry-cured ham samples were removed from the freezer at $-80^{\circ} \mathrm{C}$, where they had been placed for less than one month, for practical reasons, and then placed in a cooler maintained at $4{ }^{\circ} \mathrm{C}$ to thaw for approximately $24 \mathrm{~h}$. Given the frozen conditions (very low temperature and short 
duration of frozen storage), it can be reasonably concluded that the texture of the samples had not changed too much, although there is no real agreement, in the literature, regarding the effect of freezing on meat texture (Leygonie, Britz, \& Hoffman, 2012; Vieira, Diaz, Martinez, \& Garcia-Cachan, 2009, among others). A universal Texture Analyser TA.XT plus (Stable MicroSystems Ltd., Surrey, England) was used to perform the texture profile analysis (TPA) test (Bourne, 2002), at room temperature. Duplicate cubes $10 \times 10 \times 10 \mathrm{~mm}$ of SM and BF muscles were analysed. The $10 \mathrm{~mm}$-high cubic samples were placed so that the fibre bundles were oriented parallel to the compression plate surface (flat plunger $50 \mathrm{~mm}$ in diameter), and were then compressed axially twice to $50 \%$ of their original height, with a time interval of $2 \mathrm{~s}$ between the two successive compressions. Force-time curves were recorded with a $15 \mathrm{~kg}$ load cell applied at a crosshead speed of $1 \mathrm{~mm} / \mathrm{s}$. The following TPA parameters were obtained, using the specific software package delivered with the experimental device: hardness, fragility, springiness, adhesiveness, and cohesiveness. Hardness was defined by peak force during the first compression cycle and expressed in $\mathrm{N}$, and fragility by the ratio of the peak force during the second compression cycle to the first-obtained peak force. Cohesiveness was calculated as the ratio of the area under the second curve to the area under the first curve. Springiness was defined as the ratio of the time recorded between the start of the second area and the second probe reversal to the time recorded between the start of the first area and the first probe reversal. Adhesiveness corresponded to the "negative" area under the curve obtained between the two cycles, and expressed in N.s. The mean of the replicates of each sample was used for statistical analyses.

\subsection{Physicochemical analyses}

To determine the salt content, samples $(1 \mathrm{~g})$ were homogenised (Ultra-Turrax system, Ika, Germany) with $10 \mathrm{ml}$ of ultrapure water. After a $2 \mathrm{~h}$ rest period, the homogenate was centrifuged at $11,300 \mathrm{~g}$ for $10 \mathrm{~min}$ at room temperature (MiniSpin Plus, Eppendorf, France). The supernatant was recovered, diluted in ultrapure water, and run through an ion chromatography system (850 professional IC, Metrohm France SAS, France) to measure (systematically) chloride ion and sodium ion contents. The $\mathrm{NaCl}$ content (\%) was then calculated from these two values, with differences lower than $0.17 \%$ (in absolute value of $\mathrm{NaCl}$ content) between the two. We finally chose the value of $\mathrm{NaCl}$ content calculated from the chloride ion determination since no substitute salts $\left(\mathrm{KCl}\right.$, or $\left.\mathrm{MgCl}_{2} \ldots\right)$ were added during the preparation of the Bayonne dry-cured hams.

Water content was determined by drying samples $(2-3 \mathrm{~g})$ at $104 \pm 2{ }^{\circ} \mathrm{C}$ in a controlled-temperature chamber (Model FT127U, Firlabo, France) to constant weight (AOAC, 1990), i.e. at least $24 \mathrm{~h}$. Water content was expressed on a total matter (TM) basis ( $\mathrm{kg} \mathrm{H}_{2} \mathrm{O} / \mathrm{kg} \mathrm{TM}$ ).

\subsection{Statistical analyses}

Statistical analyses were performed, using R 3.0.1 software ( $R$ Development Core Team, 2013), and the statistical packages 'car' (Fox \& Weisberg, 2011), 'HH' (Heiberger, 2013), 'leaps' (Lumkey, 2009) and the graphical package 'rgl' (Adler \& Murdoch, 2013). They were carried out at different stages of this work. First, an analysis of variance (ANOVA) was performed, at the five different times of drycured ham production, to test the effects of the processing stages and muscle types on the PI and TBARS values. When a significant effect was observed by ANOVA, the unpaired Student $t$-test was used to determine the levels of statistical significance between groups. Second, morphometry data, acquired by image analysis, was expressed as mean \pm standard error of the mean (SEM). Changes in cross section area of fibres, extracellular spaces and fibre numbers were quantitatively analysed by one-way ANOVA, and an unpaired Student $t$-test was used to determine levels of statistical significance between groups. Third, a three-way ANOVA was performed on all the data obtained for the two muscles, SM and $\mathrm{BF}$. The objective was to assess the effect of each factor (PI, water and salt content) on all the textural and structural parameters. When the $F$-test was significant $(p<0.05)$ a post hoc procedure was used: multiple comparisons among means were examined by Fisher's least significant difference (LSD) test. Multiple linear or polynomial regressions were performed to find the best model of each of the textural and structural parameters as a function of the factors studied for each muscle, and their interactions. Experimental data for all times were considered to establish these best phenomenological models. As advocated by Fox and Weisberg (2011), regression diagnostics, such as 'Component + Residual' plots, were performed to investigate non-linearity problems, hat values, Studentised residuals and Cook's distances to identify outlier points, and finally model factor selection by exhaustive search, forward or backward stepwise, or sequential replacement (Mallows's Cp and Schwartz's information criterion: BlC).

\section{Results and discussion}

\subsection{Time course of biochemical parameters}

\subsubsection{Proteolysis index (PI) values}

Fig. 2 shows the time course of PI values measured on samples of two types of muscles ( $\mathrm{BF}$ and $\mathrm{SM}$ ) extracted from industrial Bayonne hams, over a 12-month period. This time course of proteolysis was successfully fitted by a second-order polynomial regression; correlation coefficient $\left(R^{2}\right)$ higher than 0.99 was obtained for each muscle investigated. In addition, as shown in Fig. 2, the increase in PI value was higher in BF than in SM muscle. These results are consistent with the results obtained in a previous study (Harkouss et al., 2012), where similar coefficients of the polynomial regression of PI curves were obtained on other samples of Bayonne dry-cured hams, together with similar proteolysis levels in both muscles. Toldrá et al. (1997) and Ruiz-Ramirez et al. (2006) found similar findings, with higher PI values in BF than in SM muscle. These authors indicated that this difference in PI evolution could be explained by a higher residual moisture content in BF muscle, which permits a higher enzymatic activity of the endogenous proteases. The ANOVA showed a high significant effect of muscle and time $(p<0.001)$, with also a highly significant

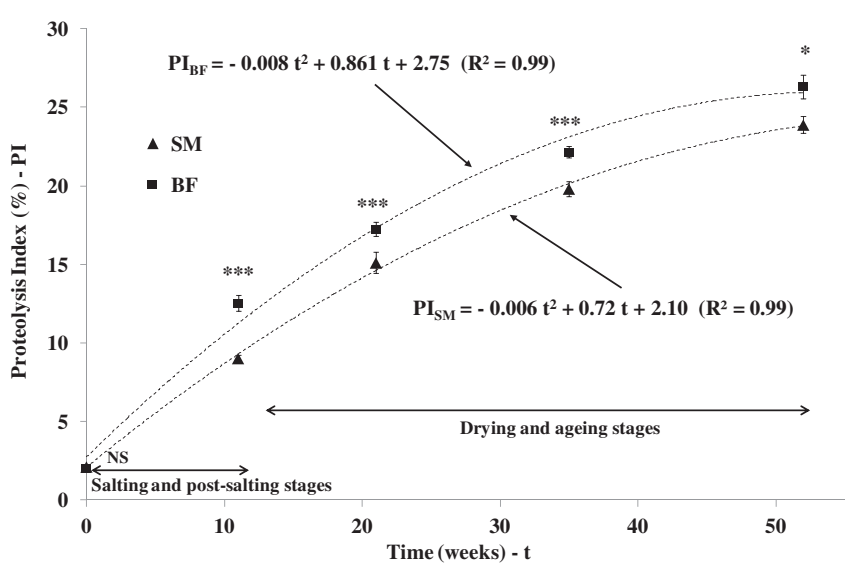

Fig. 2. Time course of proteolysis index (PI) measured on two muscles (biceps femoris and semimembranosus) of different Bayonne dry-cured hams. Values were the means \pm SEM of six independent determinations. Significance: ${ }^{* * *} p<0.001$, ${ }^{* *} p<0.01,{ }^{*} p<0.05$, NS $p \geqslant 0.05$. 
interaction between the two $(p<0.001)$, on the PI values measured on all the dry-cured ham samples.

\subsubsection{TBARS values}

Fig. 3a shows the time course of TBARS values at those stages when proteolysis degradation was assessed. A biphasic curve was observed for lipid oxidation, with an initial increase, followed by a decrease beyond 21 weeks. The initial increasing phase, until the first weeks of the drying stage, corresponds to the accumulation of aldehydes, essentially malondialdehyde and hydroxyl-nonenal which have been described to be the resultant end-products of the polyunsaturated fatty acid oxidation in meat (Gray \& Monahan, 1992). The decrease in the TBA values may occur mostly because, during long-time processing, either, as reported by Jin et al. (2012), the TBA reactive substances, mainly aldehydes, which are unstable, can then be degraded into volatile compounds, or else these aldehydes interact with free amino acid groups of proteins, leading to the formation of fluorescent Schiff bases which have been already observed during meat storage (Gatellier et al., 2007) or cooking (Gatellier, Santé-Lhoutellier, Portanguen, \& Kondjoyan, 2009). Formation of such products prevents reaction of aldehydes with TBA. Similar decrease in TBA was previously reported by Andrés, Cava, Ventanas, Muriel, and Ruiz (2004) in dry-cured Iberian hams, confirmed by Jin et al. (2012) in pork belly muscle, and shown by Gatellier et al. (2009) in cooked beef meat. Several reports have shown that typical ham flavour is generated by processes involving proteolysis and lipolysis. Nevertheless, the
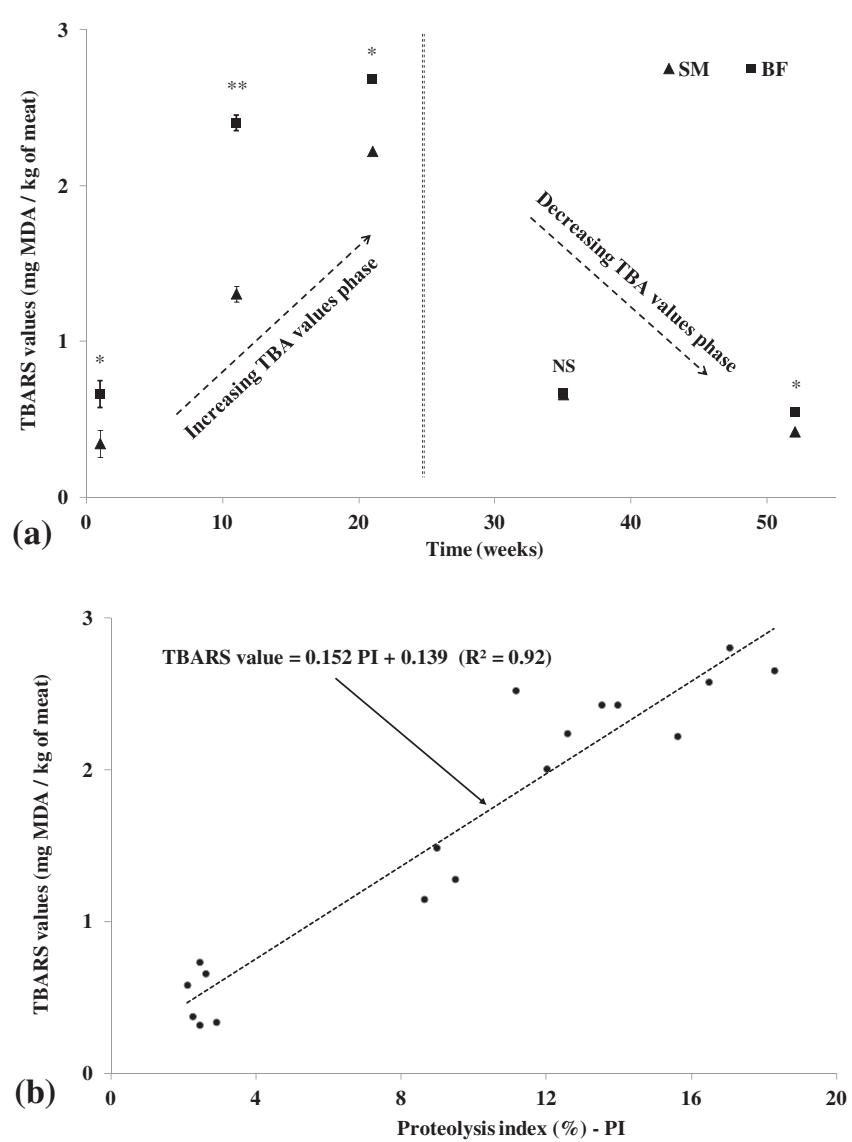

Fig. 3. Time course of lipid oxidation measured on two muscles (biceps femoris and semimembranosus) of different Bayonne dry-cured hams: (a) TBARS values; values were the means \pm SEM of three independent determinations; Significance: ${ }^{* * *} p<0.001,{ }^{* *} p<0.01,{ }^{*} p<0.05$, NS $p \geqslant 0.05$; and (b) relation between the proteolysis index and TBARS values for the first 21 weeks of dry-cured ham manufacture. high level of volatile aldehydes found in dry-cured hams suggests that lipid oxidation phenomena also play an important role in the development of the ham flavour (Garcia et al., 1991). The prooxidant effect of salt has been detected in meat products. Salt slowed proteolysis and lipolysis, but promoted lipid oxidation in dry-cured pork ham (Zhou \& Zhao, 2007). In the present study, for lipid oxidation, the ANOVA highlighted a significant effect of muscle and time $(p<0.01)$ and a highly significant interaction between the two $(p<0.001)$.

Actually, lipid oxidation may be continuously increasing during the final stage, but not well detected by TBARS. On that basis, during the increasing TBA value phase (0-21 weeks), a linear regression model was established linking proteolysis to lipid oxidation, whatever the muscle type (Fig. 3b).

We note that the correlation reported in Fig. $3 \mathrm{~b}$ is clearly valid only so long as the PI determinations are performed under the conditions described above. Other protocols will require a new formula.

\subsection{Time course of structural parameters}

Accurate quantitative analysis of the microscopy images has revealed that the cross sectional area of muscle fibres decreased by about $35 \%$ and $39 \%$ for BF and SM muscles, respectively, during the first 21 weeks of processing, and then stabilised for both (Fig. 4a). Regarding the extracellular spaces (ECS), results showed that these were minimal after 11 weeks of processing (93\% and $72 \%$ decreases for BF and SM, respectively), and again came close to values for the fresh muscle during the subsequent stages. Overall, similar behaviour, in terms of time course of ECS, was detected in both $\mathrm{BF}$ and SM muscles (Fig. 4b). This intense decrease in the ECS seems not to be associated with cell swelling, since their cross section area did not increase. It more probably results from the evacuation of the water, initially contained in the cells and ECS, toward the outside of the muscle. This hypothesis is confirmed by the increase in the fibre numbers, which reflects the surface reduction of the muscle fibres related to the water release (Fig. 4c). During the subsequent weeks of processing, the decrease in cross sectional fibre area was associated with an increase in the ECS, which implies a lateral cell contraction. This observation is probably attributable to an intracellular water loss during the drying stage. In contrast to $\mathrm{BF}$, the significant surface reduction of the SM fibres between 35 and 52 weeks of processing is probably related to the external position of this muscle, where the water transfers are correspondingly higher than those for the internal BF muscle (Monin et al., 1997).

The surface area of the connective tissue increased significantly following the salting, for both muscles (data not shown). This is related to the decrease in the volume of muscle during the drying, which increases the relative proportion of the extracellular matrix. It is also possible that certain essential proteins of the extracellular matrix could be partially distorted because of the increase in the ionic strength. These molecular modifications could lead to an expansion of the connective tissue, thus increasing its calculated surface area.

As a result, the dry-cured ham processing gives rise to dramatic structural modifications of muscle tissue and fibres. Generally speaking, BF and SM showed the same trends in their time course. To complete this work, it would be of interest to study the structural modifications by electron microscopy, in order to gain a better understanding of how salting modifies the muscular ultrastructure, and to obtain more relevant information about mechanisms involved during all the stages in the dry-curing ham process. 

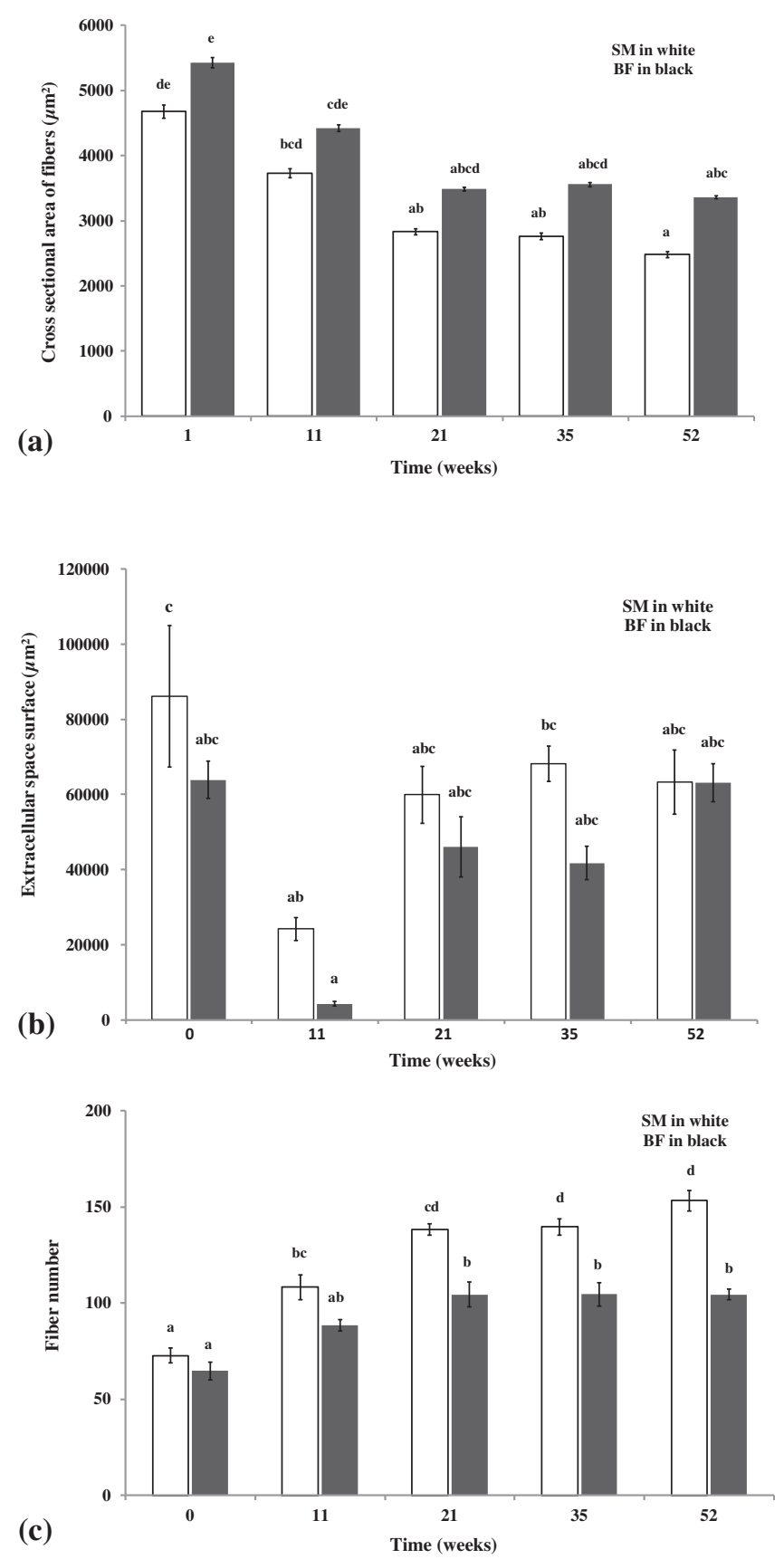

Fig. 4. Time course of three structural parameters investigated in this study on two muscles (biceps femoris and semimembranosus) of different Bayonne dry-cured hams: (a) cross sectional fibre area; (b) extracellular space surface area; and (c) fibre numbers. Values not bearing common superscripts for each muscle differed significantly $(p<0.05)$.

\subsection{Time course of textural parameters}

Table 1 shows how the mean values of the water and salt contents and of the five textural parameters measured, for the SM and $\mathrm{BF}$ pork muscles, are modified according to the stage of the manufacturing process for dry-cured ham. Accurate analysis of results reveals that hardness of dry-cured ham samples increased when water content strongly decreased $(p<0.001$ for SM and BF muscles), as soon as the salting and post-salting stages, occurring at low temperature, were complete. Hardness thus increased significantly between 10 and 52 weeks of processing ( $p<0.001$ for SM muscle, but $p=0.43$ for BF muscle). Similar behaviour was found by Cilla, Martinez, Beltran, and Roncales (2005) in Spanish drycured ham, with a longer ripening (up to 26 months). In addition, the hardness values of Bayonne dry-cured ham samples were approximately the same for both muscles, SM and BF (Table 1). These results are in agreement with the observations of Serra et al. (2005), who found an increase in hardness with decreasing water content values in BF muscle of Spanish dry-cured ham. Cohesiveness tended to be higher in SM than in BF muscle at high water content values (but with no significant difference at $p<0.05$ ), but had approximately the same value at the final stage of the process (Table 1). Similar results were reported by Ruiz-Ramirez et al. (2006) in the first stages of the dry-cured ham process, while they noted somewhat lower values at the final stages of processing. The same behaviour was detected for both muscles throughout the process. Adhesiveness increased with time in both muscles $(p<0.05$ for SM muscle, and $p<0.01$ for BF muscle), but the SM values were higher, especially at the final stages of the dry-curing process. Springiness tended to decrease when PI increased ( $p<0.001$ for SM muscle, but $p=0.38$ for BF muscle), and this particular behaviour was observed in both muscles, with lower values for SM (Table 1). Andronikov, Gasperlin, Polak, and Zlender (2013) investigated how the fresh ham weight and the amount of salt added during processing affect the technological, sensorial and physicochemical qualities of Slovenian dry-cured hams, over a one year-period of dry-curing processing. These authors globally noted that SM and BF muscles behave differently in terms of their relationships among proteolysis, water content, salt content and texture. They concluded that light and low salt dry-cured hams tend to be less hard, dry and adhesive, and more pasty and crumbly, when compared to heavy or normally salted dry-cured hams (Andronikov et al., 2013).

\subsection{Results of multivariate statistical analysis}

For each muscle, ANOVA allowed the effect of several factors on the different textural and structural properties to be assessed (Table 2). It showed that PI had a highly significant effect on the extracellular spaces and the cross sectional area for BF muscle $(p<0.001)$, and a significant effect for SM muscle $(p<0.05)$. PI also had a very significant effect on the fragility of BF muscle and the springiness of SM muscle $(p<0.01)$. The water content had a highly significant effect on the hardness for BF muscle $(p<0.001)$, and a significant effect on the cross sectional area and the extracellular spaces for SM muscle $(p<0.05)$. Analysis of the results of the ANOVA showed that salt content had a highly significant effect on the adhesiveness for SM muscle and on the extracellular spaces for BF muscle $(p<0.01)$ and a significant effect on the hardness for both muscles $(p<0.05)$.

By means of multiple polynomial regressions, different structural and textural models were then built, for SM and BF muscles, for the entire dry-cured ham production process. Table 2 contains all the coefficients, statistically calculated to build these models, which allow the textural and structural parameters investigated to be quantified from knowledge of the PI values, the water and salt contents, and their interaction.

In the present study, the 'hardness' model, as an example for a textural model, and the fibre numbers model, as an example of a structural model, established for the SM muscle are reported. The $R$-squared coefficients determined for these two models are relatively high: 0.87 and 0.84 , respectively, which means that the phenomenological models that give these two textural and structural parameters fit the experimental data closely:

Fibre Number $_{\text {SM }}=551.55+2.12 \mathrm{PI}-6.41 \mathrm{~W}-84.18 \mathrm{~S}+1.16 \mathrm{~S} . \mathrm{W}$ 
Table 1

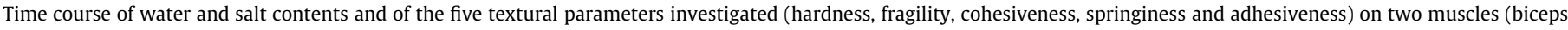

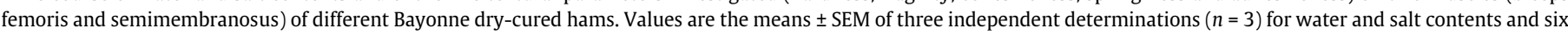
independent determinations $(n=6)$ for the textural parameters. Values not bearing common superscripts differ significantly $(p<0.05)$.

\begin{tabular}{|c|c|c|c|c|c|c|c|}
\hline Time (week) & Water content (\% TM) & Salt content (\% TM) & Hardness (N) & Fragility & Cohesiveness & Springiness & Adhesiveness (N.s) \\
\hline \multicolumn{8}{|c|}{ SM pork muscle } \\
\hline 0 & $75.5 \pm 0.7 a$ & $0.1 \pm 0.0 \mathrm{a}$ & $122 \pm 23 b$ & $0.825 \pm 0.028 a$ & $0.483 \pm 0.062 a$ & $0.857 \pm 0.008 a$ & $-3.1 \pm 1.0 \mathrm{a}$ \\
\hline 11 & $63.8 \pm 0.5 b$ & $4.9 \pm 0.2 b$ & $52 \pm 3 c$ & $0.860 \pm 0.001 \mathrm{a}$ & $0.504 \pm 0.010 \mathrm{a}$ & $0.727 \pm 0.022 b$ & $-5.1 \pm 1.8 \mathrm{a}$ \\
\hline 21 & $59.8 \pm 0.8 \mathrm{bc}$ & $4.5 \pm 0.2 b$ & $97 \pm 8 b c$ & $0.872 \pm 0.007 a$ & $0.480 \pm 0.005 a$ & $0.709 \pm 0.026 b$ & $-16.1 \pm 5.1 \mathrm{ab}$ \\
\hline 35 & $57.5 \pm 1.1 \mathrm{~cd}$ & $4.6 \pm 0.2 b$ & $108 \pm 17 b c$ & $0.887 \pm 0.005 a$ & $0.462 \pm 0.034 a$ & $0.578 \pm 0.024 c$ & $-27.1 \pm 13.3 \mathrm{ab}$ \\
\hline 52 & $53.8 \pm 1.9 \mathrm{~d}$ & $4.8 \pm 0.1 b$ & $198 \pm 14 a$ & $0.875 \pm 0.028 a$ & $0.488 \pm 0.014 \mathrm{a}$ & $0.663 \pm 0.019 b$ & $-37.1 \pm 5.2 b$ \\
\hline \multicolumn{8}{|c|}{ BF pork muscle } \\
\hline 0 & $75.2 \pm 0.4 a$ & $0.1 \pm 0.0 \mathrm{a}$ & $185 \pm 41 \mathrm{a}$ & $0.813 \pm 0.021 a$ & $0.410 \pm 0.035 a$ & $0.854 \pm 0.057 a$ & $-3.3 \pm 1.3 a$ \\
\hline 11 & $70.1 \pm 1.1 b$ & $2.8 \pm 0.2 b$ & $74 \pm 7 a$ & $0.866 \pm 0.014 a$ & $0.468 \pm 0.035 a$ & $0.805 \pm 0.028 a$ & $-6.4 \pm 0.2 \mathrm{a}$ \\
\hline 21 & $68.2 \pm 0.6 b$ & $4.3 \pm 0.2 c$ & $89 \pm 18 a$ & $0.848 \pm 0.016 a$ & $0.471 \pm 0.007 a$ & $0.821 \pm 0.042 \mathrm{a}$ & $-8.5 \pm 0.9 \mathrm{ab}$ \\
\hline 35 & $65.4 \pm 0.5 c$ & $5.1 \pm 0.1 \mathrm{~d}$ & $118 \pm 52 a$ & $0.840 \pm 0.024 a$ & $0.465 \pm 0.028 a$ & $0.757 \pm 0.027 a$ & $-16.1 \pm 3.5 c$ \\
\hline 52 & $61.8 \pm 0.5 d$ & $5.5 \pm 0.2 \mathrm{~d}$ & $183 \pm 3 a$ & $0.853 \pm 0.013 a$ & $0.489 \pm 0.024 a$ & $0.751 \pm 0.001$ & $-13.3 \pm 1.1 b c$ \\
\hline
\end{tabular}

TM: total matter.

Table 2

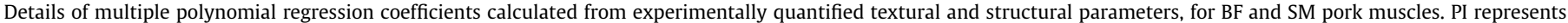
the proteolysis index (\%), $T$ the temperature $\left({ }^{\circ} \mathrm{C}\right), S$ the salt content (\% dry matter) and $W$ the water content (\% total matter).

\begin{tabular}{|c|c|c|c|c|c|c|c|c|c|}
\hline & \multicolumn{5}{|c|}{ Textural parameters } & \multicolumn{4}{|c|}{ Structural parameters } \\
\hline & Hardness & Fragility & Cohesiveness & Springiness & Adhesiveness & $\begin{array}{l}\text { Fiber } \\
\text { number }\end{array}$ & $\begin{array}{l}\text { Extracellular } \\
\text { spaces }\end{array}$ & Cross sectional area & $\begin{array}{l}\text { Connective } \\
\text { tissue area }\end{array}$ \\
\hline \multicolumn{10}{|l|}{ BF muscle } \\
\hline Intercept & $4.48 .10^{3}$ & 0.476 & 1.678 & & 6.115 & 47.80 & $-2.50 .10^{6}$ & $6.71 .10^{3}$ & \\
\hline$(\mathrm{PI})^{\wedge 0.5}$ & $9.99 .10^{2}$ & $1.058^{*}$ & 0.765 & & -9.396 & 41.82 & - & $-2330.3^{* * *}$ & \\
\hline PI & $-7.35 .10^{2 *}$ & $-0.62^{* *}$ & -0.529 & & - & - & $-2.33 .10^{4 * * *}$ & - & \\
\hline $\mathrm{PI}^{2}$ & - & - & - & & - & - & $514.2^{* * *}$ & - & \\
\hline W & $-60.63^{* * *}$ & $4.30 .10^{-4}$ & -0.020 & & - & - & $4.77 .10^{3}$ & - & \\
\hline$S$ & $-89.16^{*}$ & 0.233 & - & & 3.80 & - & $4.91 .10^{4 * *}$ & - & \\
\hline W S & - & $3.49 .10^{-3}$ & - & & - & - & - & - & \\
\hline$R^{2}$ & 0.81 & 0.67 & 0.54 & & 0.60 & 0.47 & 0.77 & 0.58 & \\
\hline Adjusted $R^{2}$ & 0.73 & 0.46 & 0.40 & $<0.25$ & 0.52 & 0.43 & 0.68 & 0.55 & $<0.25$ \\
\hline RSE & 37 & 0.026 & 0.041 & & 3.98 & 17.6 & $1.57 .10^{4}$ & 784.6 & \\
\hline \multicolumn{10}{|l|}{ SM muscle } \\
\hline Intercept & $-7.77 .10^{2}$ & -0.292 & & 0.932 & $-5.19 .10^{2}$ & 551.55 & $2.74 .10^{6}$ & $-3.29 .10^{4}$ & \\
\hline$(\mathrm{PI})^{\wedge 0.5}$ & - & $1.086^{*}$ & & - & - & - & $-1.47 .10^{6}$ & $1.57 .10^{4}$ & \\
\hline PI & -2.956 & $-0.483^{*}$ & & $-0.030^{* *}$ & 4.682 & 2.12 & $6.44 .10^{5 *}$ & $-7.56 .10^{3}$ & \\
\hline $\mathrm{PI}^{2}$ & 0.258 & - & & $7.35 .10^{-4}$ & -0.108 & - & - & - & \\
\hline W & 12.05 & 0.010 & & - & 6.778 & -6.41 & $-2.89 .10^{4 *}$ & $4.33 .10^{2 *}$ & \\
\hline S & $2.42 .10^{2 *}$ & 0.166 & & - & $124.2^{* *}$ & -84.18 & $-3.60 .10^{5 *}$ & $5.22 .10^{3}$ & \\
\hline W S & -3.57 & -0.0029 & & - & -1.759 & 1.16 & $5.49 .10^{3}$ & -79.09 & \\
\hline$R^{2}$ & 0.87 & 0.68 & & 0.75 & 0.79 & 0.84 & 0.66 & 0.79 & \\
\hline Adjusted $R^{2}$ & 0.80 & 0.51 & $<0.25$ & 0.70 & 0.68 & 0.77 & 0.47 & 0.67 & $<0.25$ \\
\hline RSE & 24.2 & 0.025 & & 0.055 & 9.9 & 15.7 & $3.20 .10^{4}$ & $6.16 .10^{2}$ & \\
\hline
\end{tabular}

RSE: Residual Standard Error/Significance: ${ }^{* * *} p<0.001,{ }^{* *} p<0.01,{ }^{*} p<0.05$.

Examples of phenomenological models that can be built:

Hardness $\mathrm{SM}_{\mathrm{M}}=-7.77 .10^{2}-2.956 \mathrm{PI}+0.258 \mathrm{PI}^{2}+12.05 \mathrm{~W}+2.42 .10^{2} \mathrm{~S}-3.57 \mathrm{~W} . \mathrm{S}$

Fibre Number $_{\mathrm{SM}}=551.55+2.12 \mathrm{PI}-6.41 \mathrm{~W}-84.18 \mathrm{~S}+1.16 \mathrm{~S} . \mathrm{W}$

$$
\begin{aligned}
\text { HardnesS }_{\mathrm{SM}}= & -7.77 .10^{2}-2.956 \mathrm{PI}+0.258 \mathrm{PI}^{2}+12.05 \mathrm{~W} \\
& +2.42 .10^{2} S-3.57 W . S
\end{aligned}
$$

where PI is the proteolysis index (\%), S is the salt content (\% DM) and $W$ is the water content (\% TM).

For the first time, different quantitative structural models, based on PI values, water and salt contents and their interaction, are established that should remain valid throughout the dry-cured ham process. The results in Table 2 show that structural properties are strongly affected by all these factors and, in particular, the extracellular space surface area. The PI factor was present in all the structural models, showing its effective and crucial role in structural changes during the entire dry-cured ham process. Salt content had to be included quite often in these phenomenological models, thus showing its very marked effect, in particular on the extracellular spaces. Generally speaking, we also observed a greater role of water content in SM muscle than in BF muscle. This may be because SM muscle dries rapidly, as soon as the process begins; consequently, quantifying many structural and textural parameters of this superficial ham muscle absolutely requires taking into account water content. The interaction between water and salt contents had to be introduced in the SM structural models, whereas it was not necessary in any of the BF ones. Again, this observation could be related to the intense salt diffusion and water evaporation that occur in the SM muscle compared with the BF muscle, especially during the first stages of the process, thus leading to these differences between the two muscles, and showing again the importance of the geometrical location of the muscles in the 3D ham.

A small number of studies sought to relate some textural parameters, such as hardness or fragility, to other factors, such as PI, water content and/or salt content. We note that Ruiz-Carrascal, Ventanas, Cava, Andres, and Garcia (2000) found a negative correlation 
relating hardness to fat content in Iberian ham. During dry-curing, Del Olmo, Calzada, Gaya, and Nuňez (2013) observed a moderate increase in the texture parameters evaluated through the measurement of cutting and shear forces. These authors attributed this slight increase to a slight increase in salt content, a slight decrease in water content, and also to a progressive degradation of proteins during curing, especially in the myofibrillar fraction. In this study, we have established that hardness is related to PI, as shown in Eq. (2), in agreement with Virgili et al. (1995), who found a correlation between proteolysis and hardness in Parma dry-cured ham. The statistical analyses performed here also clearly show that PI was crucial in explaining the time course of cohesiveness for BF muscle, and springiness for SM muscle; these results confirm those of Ruiz-Ramirez et al. (2005), who reported that cohesiveness and springiness were proportional to PI values. Table 2 also shows that adhesiveness can be reasonably estimated as a function of PI values, water content and salt content, this last factor having a very significant effect on adhesiveness, in particular for SM muscle.

However, all the results reported in Table 2 need to be confirmed by further experiments, to highlight both truly significant correlations and complete absence of correlation (i.e. when adjusted $R$-squared coefficients are lower than 0.25 ). For instance, for connective tissue area, no statistical model was found for either muscle investigated. This could be because this particular structural parameter does not depend on PI or water and salt contents, but it could also be because not enough samples were analysed to establish a significant correlation. It is clear that the statistical significance of the correlations reported in Table 2 would gain from being based on a larger number of dry-cured ham samples. This is planned in future work. We must bear in mind that, in the present study, the phenomenological models reported were statistically built on the basis of experiments performed on samples extracted from 15 dry-cured hams, corresponding to three dry-cured hams and five process times. We must also bear in mind that these phenomenological models will not be used alone but in combination with a numerical finite-element model, already coupling the prediction of the physical phenomena of heat and mass transfers with the calculation of proteolysis indices, thus constituting what we call the "numerical ham" model. Even so, this study has the merit of giving, often for the first time, statistical models allowing the quantitative estimation of several structural and textural parameters as a function of proteolysis index and some basic physicochemical parameters, such as water and salt contents.

\section{Conclusion}

Quantitative information about the interrelationships among proteolysis, texture and/or structure is provided in this study by the development of several statistical models allowing the time course of some textural parameters, such as hardness, cohesiveness, springiness, fragility and adhesiveness, and of some structural parameters of dry-cured ham, such as fibre numbers, extracellular spaces and cross sectional area of muscle fibres, to be estimated, with greater or lesser accuracy, as a function of proteolysis index, salt and water contents, and their interaction. We also found a quantitative correlation between lipid oxidation and proteolysis. However, we are aware that (i) the robustness of the correlations established in this study would be improved by increasing sample size, and (ii) the accurate quantification of lipid oxidation throughout the dry-cured ham process would require measuring reactive substances other than TBARS.

The phenomenological models built and the relations found here will then be incorporated into a numerical finite-element model dedicated to predicting salt diffusion, water migration and heat transfer inside a 3D ham geometry, to simulate the time course of proteolysis, of lipid oxidation and of some textural and structural parameters throughout the dry-cured ham process. Once validated, this complete "numerical" ham model could then be used to test different scenarii to allow salt content to be reduced in dry-cured hams, while avoiding excessive proteolysis leading to a too-soft product, and preserving the textural and aromatic properties that consumers demand.

\section{Acknowledgements}

This work was funded by the Na-integrated programme (ANR09-ALIA-013-01) financed by the French National Research Agency. This paper forms part of the thesis of Rami Harkouss, who works for this research programme. We thank Riziki Ali for her participation in image analysis, Annie Venien and Raphaël Favier for their technical assistance, ADIV for measuring the textural parameters in Bayonne dry-cured ham samples, and ATT for language editing.

\section{References}

Adler, D., \& Murdoch, D. (2013). Rgl: 3D visualization device system. R package version 0.93.945. URL http://cran.r-project.org/web/packages/rgl/. (Accessed 11.09.13).

Aidos, I., Lourenco, S., Van der Padt, A., Luten, J. B., \& Boom, R. M. (2002). Stability of crude herring oil produced from fresh byproducts: influence of temperature during storage. Journal of Food Science, 67(9), 3314-3320.

Andrés, A. I., Cava, R., Ventanas, J., Muriel, E., \& Ruiz, J. (2004). Lipid oxidative changes throughout the ripening of dry-cured Iberian hams with different salt contents and processing conditions. Food Chemistry, 84(3), 375-381.

Andronikov, D., Gasperlin, L., Polak, T., \& Zlender, B. (2013). Texture and quality parameters of Slovenian dry-cured ham (Kraski prsut) according to mass and salt levels. Food Technology and Biotechnology, 51(1), 112-122.

AOAC (1990). Association of official analytical chemist (15th ed.), (pp. 931-935). Virginia: Arlington.

Arnau, J., Gou, P., \& Comaposada, J. (2003). Effect of the relative humidity of drying air during the resting period on the composition and appearance of dry-cured ham surface. Meat Science, 65, 1275-1280.

Arnau, J., Guerrero, L., \& Gou, P. (1997). Effects of temperature during the last month of ageing and of salting time on dry-cured ham aged for six months. Journal of the Science of Food and Agriculture, 74, 193-198.

Bourne, M. C. (2002). Principles of objective texture measurement. In M. C. Bourne (Ed.), Food texture and viscosity: Concept and measurement (pp. 107-188). USA: San Diego.

Cilla, I., Martinez, L., Beltran, J. A., \& Roncales, P. (2005). Factors affecting acceptability of dry-cured ham throughout extended maturation under "bodega" conditions. Meat Science, 69, 789-795.

Cordero, M. R., \& Zumalacarregui, J. M. (2000). Characterization of micrococcaceae isolated from salt used for Spanish dry-cured ham. Letters in Applied Microbiology, 31(4), 303-306.

Del Olmo, A., Calzada, J., Gaya, P., \& Nuňez, M. (2013). Proteolysis, texture, and sensory characteristics of Serrano hams from Duroc and Large White pigs during dry-curing. Journal of Food Science, 78(3), C416-C424.

Desmond, E. (2006). Reducing salt: a challenge for the meat industry. Meat Science, $74,188-196$.

Fox, J., \& Weisberg, S. (2011). An R companion to applied regression. 2nd Edition. Thousand Oaks CA: Sage. URL http://socserv.socsci.mcmaster.ca/jfox/Books/ Companion. (Accessed 11.09.13).

Fritz, J. D., Mitchell, M. C., Marsh, B. B., \& Greaser, M. L. (1993). Titin content of beef in relation to tenderness. Meat Science, 33(1), 41-50.

Garcra, C., Berdagué, J. L., Antequera, T., Lopez-Bote, C., CÓrdoba, J. J., \& Ventanas, J. (1991). Volatile compounds of dry-cured Iberian ham. Food Chemistry, 41, 23-32.

Garcra-Garrido, J. A., Quiles-Zafra, R., Tapiador, J., \& Luque de Castro, M. D. (2000). Activity of cathepsin B, D, H and L in Spanish dry-cured ham of normal and defective texture. Meat Science, 56(1), 1-6.

Gatellier, P., Santé-Lhoutellier, V., Portanguen, S., \& Kondjoyan, A. (2009). Use of meat fluorescence emission as a marker of oxidation promoted by cooking. Meat Science, 83, 651-656.

Gatellier, P., Gomez, S., Gigaud, V., Berri, C., Le Bihan-Duval, E., \& Santé-Lhoutellier, V. (2007). Use of a fluorescent front face technique for measurement of lipid oxidation during refrigerated storage of chicken meat. Meat Science, 76, 543-547.

Gou, P., Morales, R., Serra, X., Guàrdia, M. D., \& Arnau, J. (2008). Effect of a 10-day ageing at $30^{\circ} \mathrm{C}$ on the texture of dry-cured hams processed at temperatures up to $18^{\circ} \mathrm{C}$ in relation to raw meat $\mathrm{pH}$ and salting time. Meat Science, 80 , 1333-1339.

Gray, J. I., \& Monahan, F. J. (1992). Measurement of lipid oxidation in meat and meat products. Trends in Food Science and Technology, 3, 315-319.

Harkouss, R., Mirade, P. S., \& Gatellier, P. (2012). Development of a rapid, specific and efficient procedure for the determination of proteolytic activity in dry-cured ham: definition of a new proteolysis index. Meat Science, 92, 84-88. 
Harkouss, R., Safa, H., Gatellier, P., Lebert, A., \& Mirade, P. S. (2014). Building phenomenological models that relate proteolysis in pork muscles to temperature, water and salt content. Food Chemistry, 151, 7-14.

Heiberger, R.M. (2013). HH: statistical analysis and data display. R package version 2.3.37. URL http://cran.r-project.org/web/packages/HH/. (Accessed 11.09.13).

Jin, G., He, L., Zhang, J., Yu, X., Wang, J., \& Huang, F. (2012). Effects of temperature and $\mathrm{NaCl}$ percentage on lipid oxidation in pork muscle and exploration of the controlling method using response surface methodology (RSM). Food Chemistry, $131,817-825$

Larrea, V., Perez-Munuera, I., Hernando, I., Quiles, A., \& Lluch, M. A. (2007). Chemical and structural changes in lipids during the ripening of Teruel dry-cured ham. Food Chemistry, 101, 1327-1336.

Leygonie, C., Britz, T. J., \& Hoffman, L. C. (2012). Impact of freezing and thawing on the quality of meat: review. Meat Science, 91, 93-98.

Luccia, A. D., Picariello, G., Cacace, G., Scaloni, A., Faccia, M., Liuzzi, V., et al. (2005). Proteomic analysis of water soluble and myofibrillar protein changes occurring in dry-cured hams. Meat Science, 69, 479-491.

Lumkey, T. (2009). Leaps: regression subset selection. R package version 2.9. URL http://CRAN.R-project.org/package=leaps. (Accessed 11.09.13).

Lynch, S. M., \& Frey, B. (1993). Mechanisms of copper and iron dependent oxidative modification of human low density lipoprotein. Journal of Lipid Research, 34, 1745-1751.

Mercier, Y., Gatellier, P., Viau, M., Remignon, H., \& Renerre, M. (1998). Effect of dietary fat and vitamin $\mathrm{E}$ on lipid and protein oxidation in turkey meat during storage. Meat Science, 48, 301-317.

Monin, G., Marinova, P., Talmant, A., Martin, J. F., Cornet, M., Lanore, D., et al. (1997). Chemical and structural changes in dry-cured hams (Bayonne Hams) during processing and effect of the dehairing technique. Meat Science, 47, 29-47.

Morales, R., Serra, X., Guerrero, L., \& Gou, P. (2007). Softness in dry-cured porcine biceps femoris muscles in relation to meat quality characteristics and processing conditions. Meat Science, 77, 662-669.

Morales, R., Arnau, J., Serra, X., Guerrero, L., \& Gou, P. (2008). Texture changes in drycured ham pieces by mild thermal treatments at the end of the drying process. Meat Science, 80, 231-238.

R Development Core Team (2013). R: a language and environment for statistical computing. R Foundation for Statistical Computing, Vienna, Austria. URL http:/ www.R-project.org. (Accessed 11.09.13).
Rhee, K., Smith, G. G., \& Terrell, R. N. (1983). Effect of reduction and replacement of sodium chloride on rancidity development in raw and cooked pork. Journal of Food Protection, 46(7), 578-581.

Ruiz-Carrascal, J., Ventanas, J., Cava, R., Andres, A., \& Garcia, C. (2000). Texture and appearance of dry-cured ham as affected by fat content and fatty acid composition. Food Research International, 33, 91-95.

Ruiz-Ramirez, J., Arnau, J., Serra, X., \& Gou, P. (2006). Effect of pH(24), NaCl conten and proteolysis index on the relationship between water content and texture parameters in biceps femoris and semimembranosus muscles in dry-cured ham. Meat Science, 72, 185-194.

Ruiz-Ramirez, J., Serra, X., Gou, P., \& Arnau, J. (2005). Profiles of water content, water activity and texture in crusted dry-cured loin and in non-crusted dry-cured loin. Meat Science, 69, 519-525.

Serra, X., Ruiz-Ramírez, J., Arnau, J., \& Gou, P. (2005). Texture parameters of drycured ham $\mathrm{m}$. biceps femoris samples dried at different levels as a function of water activity and water content. Meat Science, 69, 249-254.

Sforza, S., Pigazzani, A., Motti, M., Porta, C., Virgili, R., Galaverna, G., et al. (2001). Oligopeptides and free amino acids in Parma hams of known cathepsin B activity. Food Chemistry, 75(3), 267-273.

Toldrá, F. (1998). Proteolysis and lipolysis in flavour development of dry-cured meat products. Meat Science, 49(Suppl. 1), 101-110.

Toldrá, F., Flores, M., \& Sanz, Y. (1997). Dry-cured ham flavour: enzymatic generation and process influence. Food Chemistry, 59(4), 523-530.

Vieira, C., Diaz, M. T., Martinez, B., \& Garcia-Cachan, M. D. (2009). Effect of frozen storage conditions (temperature and length of storage) on microbiological and sensory quality of rustic crossbred beef at different states of ageing. Meat Science, 83, 398-404.

Virgili, R., Parolari, G., Schivazappa, C., Soresi-Bordini, C., \& Borri, M. (1995). Sensory and texture quality of dry-cured ham as affected by endogenous cathepsin B activity and muscle composition. Journal of Food Science, 60, 1183-1186.

Zhao, G. M., Tian, W., Liu, Y. X., Zhou, G. H., Xu, X. L., \& Li, M. Y. (2008). Proteolysis in biceps femoris during Jinhua ham processing. Meat Science, 79(1), 39-45.

Zhao, G. M., Zhou, G. H., Wang, Y. L., Xu, X. L., Huan, Y. J., \& Wu, J. Q. (2005). Timerelated changes in cathepsin $\mathrm{B}$ and $\mathrm{L}$ activities during processing of Jinhua ham as a function of pH, salt and temperature. Meat Science, 70, 381-388.

Zhou, G. H., \& Zhao, G. M. (2007). Biochemical changes during processing of traditional Jinhua ham. Meat Science, 77, 114-120. 